\title{
Alexithymia and therapeutic alliance: a multiple case study comparing good and poor outcome cases
}

\author{
Ana Catarina Nunes da Silva, ${ }^{1}$ António Branco Vasco, ${ }^{1}$ Jeanne C. Watson ${ }^{2}$ \\ ${ }^{1}$ Department of Cognitive, Behavioral and Integrative Psychotherapy, Faculty of Psychology, University of Lisbon, Portugal; ${ }^{2}$ Ontario \\ Institute for Studies in Education, University of Toronto, Canada
}

\begin{abstract}
Alexithymia has been associated with poor outcomes in psychotherapy. This association has been attributed to a difficulty in patients expressing emotions, engaging in emotional tasks and also poor therapeutic alliances. This study aims to better understand alexithymic patients in psychotherapy. A multiple case study design was used. Cases were selected from a larger research project considering their alexithymia level and outcome status, based on the reliable change index and the client perspective on change. Four cases are presented: with and without alexithymia with good and poor outcome. The therapeutic alliance was included as a process measure, evaluated from both client and therapist. At the end a semi structured interview was conducted with both participants, individually. The analysis concerned the integration and triangulation of the therapist and client experience for each case. Each patient was briefly presented and then a focus was made regarding the perception of both participants on the therapeutic alliance and the emotional processing and change process of the client. Both alexithymic cases and the non-alexithymic poor outcome case showed difficulties in the therapeutic alliance, especially from the perspective of the therapist. In these cases, emotional impairments may have contributed to a poor therapeutic alliance, impacting on the outcome. We suggest that a great focus on the therapeutic alliance with alexithymic patients

Correspondence: Ana Catarina Nunes da Silva, Department of Cognitive, Behavioral and Integrative Psychotherapy, Faculty of Psychology, University of Lisbon, Alameda da Universidade 1649-013 Lisbon, Portugal. may increase the quality of treatment and it may be more useful for case conceptualization to consider each feature of the alexithymia construct individual.
\end{abstract}

Tel.: +351.939442906.

E-mail: AnaCatarinaNS@gmail.com

Citation: Silva, A.N., Vasco, A.B., \& Watson, J.C. Alexithymia and therapeutic alliance: a multiple case study comparing good and poor outcome cases. Research in Psychotherapy: Psychopathology, Process and Outcome, 21(2), 83-97. doi: 10.4081/ripppo.2018.313

Contributions: ANS, ABV JCW, conception, design and final approval of the manuscript; ANS, analysis and writing-original draft preparation; $\mathrm{ANS}, \mathrm{ABV}$, interpretation of data; $\mathrm{ABV}, \mathrm{JCW}$, writing, critical review.

Conflict of interest: the authors declare no potential conflict of interest.

Acknowledgments: the authors are grateful to all the participants in this study.

Funding: the preparation of this paper was conducted during the period that the first author was supported by a FCT grant SFRH/BD/65066/2009.

Received for publication: 27 May 2018.

Revision received: 20 June 2018.

Accepted for publication: 10 July 2018.

This work is licensed under a Creative Commons Attribution NonCommercial 4.0 License (CC BY-NC 4.0).

C Copyright A.N. Silva et al., 2018

Licensee PAGEPress, Italy

Research in Psychotherapy:

Psychopathology, Process and Outcome 2018; 21:83-97

doi:10.4081/ripppo.2018.313
Key words: Alexithymia; Therapeutic alliance; Emotional processing; Poor outcome; Clinical case studies.

\section{Introduction}

The term alexithymia was first used by Sifneos (1973) to designate a group of cognitive and affective characteristics typical of many patients with somatic disorders. It was considered that the inability to symbolically represent an emotion meant that individuals with alexithymia would not be able to modulate their distress thereby contributing to impaired physical well-being. Taylor, Bagby and Parker (1997) suggested that the concept is defined by three fundamental elements, including: difficulty identifying feelings; difficulty in comunicating feelings and externally-oriented thinking (for a recent review see Taylor, Bagby, \& Parker, 2016).

Although initially linked to psychosomatic disorders, alexithymia was soon identified in a number of other conditions, such as eating disorders (e.g., Petterson, 2004), substance abuse and dependence (e.g., Uzun, 2003), anxiety disorders and depression (e.g., Zeitlan \& Mcnally, 1993), post-traumatic stress disorder (e.g., Brady, Bujarski, Feldner, \& Pyne, 2017), personality disorders (e.g., De Panfilis, Ossola, Tonna, Catania, \& Marchesi, 2015), and also autism spectrum disorders, particularly Asperger' syndrome (e.g., Hill, Berthoz, \& Frith, 2004). It should 
be noted that alexithymia does not appear to be a substantive feature of any of these disorders, but instead a related, comorbid condition (Taylor, 1984). So, it is important not to think of alexithymia as a psychiatric disorder, but instead as a psychological characteristic of thought, feelings and underlying processing. This is a more comprehensive way of thinking of alexithymia, making it more useful for therapy and for clinical decision making (Ogrodniczuk, Piper, \& Joyce, 2005; Silva, Vasco, \& Watson, 2013).

Despite its prevalence in clinical population, often alexithymia is not taken into consideration in psychotherapy. Ogrodniczuk (2007) drew attention to the fact that, over the years, research on alexithymia has focused more on its aetiology, neglecting research on better ways to intervene in psychotherapy. Some speculation has been made regarding the prognostic power of alexithymia across treatment modalities (e.g., de Haan, Schellekens, van der Palen, Verkes Buitelaar, \& De Jong, 2012) but it is not clear its differential impact. Alexithymia has been associated with poor outcomes in psychotherapy (e.g. McCallum, Piper, Ogrodniczuk, \& Joyce, 2003; Leweke, Bausch, Leichsenring, Walter, \& Stingl, 2009), which seems to be independent from the type of therapy. The reaction of the therapist to the patient partially mediated the difficulties in communicating feelings and the externally oriented thinking style in the outcome (Ogrodniczuk et al., 2005). This means that, patients with alexithymia may have poorer outcomes in part because their therapists perceive them as having less value and less compatibility with them. Therapists may unintentionally express these feelings, which may affect the patient's experience of therapy, contributing to poor outcomes.

Findings suggest that alexithymia is partly modifiable with therapeutic interventions. Studies that directly targeted alexithymic symptoms tend to report significant reductions in alexithymia scores following treatment, whereas studies that measured changes in alexithymia but did not employ any psychological interventions specifically intended to treat alexithymia have more inconsistent results (for a review see Cameron, Ogrodniczuk, \& Hadjipavlou, 2014). For example, in a study with an outpatient psychiatric sample (McGillivray, Becerra, \& Harms, 2018) a high level of relative stability was observed in alexithymia scores, independent of change in psychological distress severity, but a reduction in alexithymia during treatment was a significant predictor of a reduction in psychological distress over the course of therapy. In other study, aimed to assess the effectiveness of intensive psychological treatment for eating disorders, there was an effectiveness of psychotherapy as regards dissociative moments, impulsivity and body dissatisfaction, but not alexithymia (Caslini, Rivolta, Zappa, Carrà, \& Clerici, 2015).

A study trying to demonstrate the efficacy of hypnosis in decreasing alexithymia indicated that changes in mood states are not involved in the change in alexithymia scores. This is contrary to other studies, suggesting that it is possible to exert an effect upon alexithymia without targeting a decrease in anxiety or depression scores and upon alexithymic people with no anxiety or depression problems, as anxiety and depression are not the therapeutic determinant of the therapeutic response (Gay, Hanin, \& Luminet, 2008).

Grabe et al. (2008) developed an inpatient treatment program including psychodynamic group therapy, and found a significant reduction in psychopathology and alexithymia. Nevertheless, these patients continued to suffer from higher distress at discharge than non-alexithymics. Levant, Halter, Hayden, and Williams (2009) also tried to overcome this difficulty developing the Alexithymia Reduction Treatment. It was a six-session manualized psychoeducational group intervention, which was administered in the first six session of their therapeutic group (Levant, Williams \& Hayden, 2008). Each session had homework assignments: i) Male emotion socialization; ii) Developing a vocabulary for emotions; iii) Learning to read the emotions of others; iv) Keeping an emotional response log; v) practice; and vi) Moving to Deeper Issues. Participants in the treatment group demonstrated significant reductions in normative male alexithymia and the endorsement of traditional masculine ideology from pre-test to post-test when compared to the treatment as usual group. Nevertheless, this study presented two major limitations: its focus on the male gender and that the findings may be due to the differences in the settings and participants as much as to differences between the treatments (Levant et al., 2009).

A more recent study (Dong, Ju, Qiu, \& Feng, 2017) tried to explore the intervention efficacy in middle school students of different group treatment on three types of alexithymia, including affective, cognitive and synthesize alexithymia groups. After interventions, all participants got significantly better scores on both affective and synthesize dimensions of alexithymia, which sustained to three months later. Significant changes on cognitive scores between preand post-test were found in students who suffer cognitive or synthesize alexithymia, but not in affective or the control group. This suggests that targeted group treatment is effective for different types of alexithymia.

Taking into account these results, it seems that the different components of alexithymic functioning play an important role in psychotherapy, emphasizing the need for an adequate therapeutic approach. It also illustrates the need for more studies on the subject, not only regarding outcome, but also considering how the therapeutic process develops with these patients. Ogrodniczuk (2007) stressed the importance of identifying forms of therapeutic communication that effectively reduce alexithymia so that psychotherapy could be more responsive to the needs of these patients. In line with this idea, Taylor (2000) suggested that the use of psychotherapies involving specific techniques to increase emotional awareness and integrating symbolic elements of emotional schemes may be ben- 
eficial in reducing alexithymic characteristics. Interventions that promote the mental representation of emotions may be useful Silva, Vasco, \& Watson, 2013). Although attempts are being made to identify an effective treatment to reduce alexithymia, since it has been described not as a psychiatric disorder, but as a way of thinking and feeling, it seems more useful to choose and integrate interventions from the numerous existing models. It should also be noted that patients do not come to therapy complaining about alexithymia but instead of anxiety, depression, relationships, among other complaints. We believe that, more than developing a specific treatment for alexithymic patients, a better understanding of the impact of this impairment in psychotherapy should be made.

\section{Present study}

Considering the importance of emotional processing to the change process and the therapeutic alliance with alexithymic patients, a better understanding on how alexithymia impacts the perception of the alliance and it's relation to emotional processing is essential.

A multiple case study design (Yin, 2003) is presented. Although still with limitations, case studies allow researchers to explore potentially impeding factors that are often unidentified in group comparisons (Iwakabe, 2011). Case comparisons provide a way to contrast cases, being able to compare cases with similar or even contradictory results and this adds knowledge to what one single case can offer (Iwakabe, 2011). Since there is still a lack of research on alexithymia in the therapeutic context, before developing or suggesting an adequate therapeutic approach, a deeper exploration should be made of some aspects that have been associated with the alexithymic patients' worse outcomes: emotional processing and therapeutic alliance.

Our main goal is to explore the relationship between alexithymia, therapeutic alliance, change process and the outcome taking into account both therapist and client perspectives: How do client and therapist experience the relationship? Do they perceive the difficulties in the relationship due to alexithymia? How is that different from the difficulties felt in the therapeutic alliance with other patients? What special care should be taken with alexithymic patients in psychotherapy? What may be the usefulness of the construct in case conceptualization?

\section{Materials and Methods}

\section{Participants}

Four cases were selected from a larger research project (Silva, Vasco, \& Watson, 2018). The study was approved by the ethics committee of the Faculty of Psychology of the Lisbon University and by each institution involved. It was a naturalistic study, with a convenience sample, with several therapists from public and private practice being invited to participate and invite clients starting outpatient psychotherapeutic treatment to join. This invitation was made before the first session and if the client accepted, both client and therapist signed a written consent, were assured of confidentiality and that they could leave the study at any point without interference with therapy. All therapists in that study were clinical psychologists. Five were cognitive behavioral therapists, one was brief psychodynamic, one integrative and one had psychoanalytic training. None of the authors was a therapist in this study. The outcome measures were given at the first and eighth session and then at the end of therapy or at the sixteenth session if therapy continued. None of the therapist knew the scores of their patients. An interview was conducted with all participants shortly after psychotherapy ended or after the sixteenth session. All the interviews took place in a setting chosen by the participants, which was in most cases the hospital or clinic where therapy took place. Participants were assured of confidentiality and permission to audiotape the interviews was obtained. The original sample had 12 cases: 10 good outcomes - two alexithymic, two possible alexithymic, six non alexithymic and two bad outcomes - one alexithymic and one non alexithymic. The cases could be completed, ongoing, prematurely ended or drop outs (for a characterization of the full sample see Silva, Vasco, \& Watson, 2018).

In the present study all therapists characterized themselves as cognitive behavioral. Three cases were gathered in a private practice setting and one in a public hospital (Case 2). Cases 3 and 11 had the same psychotherapist. Cases were selected considering the initial level of alexithymia (alexithimic $v s$ non-alexithymic) according to the TAS-20 and the outcome (good vs poor), in order to have two good and two poor outcome cases with and without alexithymia. Concerning outcome, both the reliable change index (RCI) and the client perspective were taken into account. The RCI (Christensen \& Mendoza, 1986; Jacobson \& Truax, 1991) can be used to compare prepost results of psychotherapy, taking into account the standard error of measurement. In the present study the adaptation done by Evans, Margison and Barkham (1998) was used. It provides the RCI below which there is $5 \%$ of the difference being due to error. This formula takes into account the reliability and standard deviation of the instrument. For both the BSI and the TAS-20, the data used came from the original Portuguese studies (BSI, Canavarro, 1999; TAS-20, Prazeres, Parker, \& Taylor, 2000). For the BSI, the RCI was 0.89 and for the TAS-20 was 12.70 . The characterization of the participants is made within the case studies. Since there were only two poor outcome cases in the original sample, one alexithymic and one non alexithymic, they were selected for this study. Cases 3 and 4 were selected as good outcome cases, since they were both complete cases, and their therapists had the same theoretical orientation as the therapists from the poor outcomes. 


\section{Measurement}

\section{Alexithymia}

The Portuguese version of the Toronto Alexithymia Scale (TAS-20) was used to measure alexithymia (Bagby, Parker, \& Taylor, 1994a, 1994b). A 20-item, self-report composed of three subscales: Difficulty Identifying Feelings (DIF), Difficulty Describing Feelings (DDF), and Externally Oriented Thinking (EOT). Items are rated on a 5-point scale, ranging from 1 (strongly disagree) to 5 (strongly agree). Scores less than or equal to 51 reflect non-alexithymia, scores of 52-60 reflect possible alexithymia, and scores of 61 or greater reflect alexithymia. The TAS-20 was translated to several different languages, and its factorial structural was validated trough different samples and cultures, showing a stable and replicable factorial structure that is congruent with the alexithymia construct (Parker, Taylor, \& Bagby, 2003a, 2003b). Analysis of the Portuguese version also supported the construct validity of the three subscales. Total score internal consistency is .79 (Prazeres et al., 2000).

\section{Severity of symptoms}

Severity of symptoms was measured using the Portuguese version of the Brief Symptom Inventory (BSI, Degoratis, 1993), a 53-item self report. It is a reduced version of the Symptom Checklist (SCL-90; Derogatis, 1975), in which participants rate the extent to which they have been disturbed in the past week by several symptoms $(0=$ not at all to $4=$ extremely). The BSI has nine subscales designed to assess individual symptom groups (e.g., somatization, depression, anxiety). In the comparison between cases, only the Global Severity Index (GSI) was used as a general measure of the severity of symptoms. The Portuguese version showed good psychometric properties with a GSI average of $1.43(S D=0.943)$ in a clinical sample. A value equal or superior to 1.7 , may point to an emotional disturbance (Canavarro, 1999).

\section{Therapeutic alliance}

Therapeutic alliance was measured with the Working Alliance Inventory - Short Form (WAI-S, Horvath \& Greenberg, 1989; Tracey \& Kokotowitc, 1989). The WAI$\mathrm{S}$ is composed by three dimensions regarding the conceptualization of Bordin (1979): bond, agreement between therapist and patient on goals and tasks. Participants report the frequency of feeling and thoughts in relation to the other element of the therapeutic dyad, on a likert scale (from 1 never to 7 always). The short version has 12 items, four for each dimension (Tracey \& Kokotovic, 1989). In this study only the global score was used. Internal consistency for the Portuguese adaptation is .89 for the patient version and .85 for the therapist version (Machado \& Horvath, 1999).

\section{Interview}

Two individual semi-structured script interviews were developed with the goal of assessing the perspective of therapist and client on the alliance, emotional processing and change process. Table 1 presents the major questions and themes of these interviews.

\section{Procedure}

The time frame considered in this study was from the first to the $16^{\text {th }}$ session. This interval allowed for the inclusion of the minimum number of sessions in which the

Table 1. Brief versions of the scripts of the therapist and client interview protocol.

\begin{tabular}{|c|c|}
\hline Brief Ve & rief Versi \\
\hline \multicolumn{2}{|c|}{ Question \& Goal } \\
\hline $0-$ Could you tell $\mathrm{n}$ & $\begin{array}{l}0 \text { - Could you tell how was it for you being in therapy? Was it the first } \\
\text { time? [Warm-up question] }\end{array}$ \\
\hline $\begin{array}{l}1 \text { - What were the most meaningful aspects of the therapy? [Identificat } \\
\text { of central themes or processes] }\end{array}$ & \multirow{2}{*}{$\begin{array}{l}1 \text { - What were the most meaningful aspects of the therapy? [Identification } \\
\text { of central themes or processes] }\end{array}$} \\
\hline 2 - How did change occur in psychotherapy? [Mode/Type of change] & \\
\hline \multirow{2}{*}{$\begin{array}{l}\text { 3- How did emotional change occur? [Specific change on emotional pro- } \\
\text { cessing] }\end{array}$} & $2-$ How did cha \\
\hline & \multirow{2}{*}{$\begin{array}{l}\text { 3- What do you feel you have gained from being in therapy? [perception } \\
\text { on gains concerning therapy vs changes outside] }\end{array}$} \\
\hline \multirow{2}{*}{$\begin{array}{l}\text { 4- How was the therapeutic alliance? How did it evolve? [Characteriza- } \\
\text { tion of therapeutic alliance thought therapy] }\end{array}$} & \\
\hline & \multirow{2}{*}{$\begin{array}{l}\text { 4- How did emotional change occur? [Specific change on emotional pro- } \\
\text { cessing] }\end{array}$} \\
\hline \multirow{2}{*}{$\begin{array}{l}5 \text { - What, in the client, facilitated change? [Client processes relevant in } \\
\text { change] }\end{array}$} & \\
\hline & \multirow{2}{*}{$\begin{array}{l}\text { - How did you regulate emotion? How do you regulate them now? [emo- } \\
\text { tion regulation perception and change process] }\end{array}$} \\
\hline the client, made change harder? & \\
\hline \multirow{2}{*}{$\begin{array}{l}7 \text { - Did you consider that this client had some indicator of personality di- } \\
\text { sorder? }\end{array}$} & 6 - Do you consider yourself a more rational or $n$ \\
\hline & \multirow{2}{*}{$\begin{array}{l}7 \text { - How was the therapeutic alliance? How did it evolve? [Characteriza- } \\
\text { tion of therapeutic alliance thought therapy] }\end{array}$} \\
\hline Did you & \\
\hline
\end{tabular}


greatest reduction of symptoms occurs and simultaneously allowed for the observation of deeper changes (e.g., Barkham et al., 2006). If psychotherapy ended before the $16^{\text {th }}$ session, the client was still included. If psychotherapy extended beyond the $16^{\text {th }}$ session, the client was invited to a final assessment, and no further sessions were assessed. An assessment with standardized self-reports for the outcome measures (symptoms and alexithymia) was made at the first, eighth session and then at the end of therapy or at the sixteenth session if therapy continued (Table 2$)$. Every two sessions $\left(2^{\text {nd }}, 4^{\text {th }}, 6^{\text {th }} \ldots\right)$ data was collected regarding the therapeutic alliance from both client and therapist. At the end of the study a semi structured interview was conducted with both participants, individually.

\section{Data analysis}

The first step of analysis concerned the integration and triangulation of therapist and client experience for each case. There was a focus on the perception of both participants on change process, the evolution of the therapeutic alliance and the emotional experience of the client. Interviews were explored using thematic analysis (Braun \& Clarke, 2006) always contrasting alexithymic and non alexithymic cases, and the results were used to augment and cross validate the quantitative data. Each interview was transcribed and the transcript was read and reread. Three questions guided the analysis: How did the participants perceive the therapeutic alliance? How did the client perceive and talk about emotions? How did participants perceive the change process?

When analyzing the interviews, we wanted to stay as close to the informant's concrete and contextually anchored experience as possible, while exploring their own views of what felt significant in the therapeutic process (Elliot \& Shapiro, 1992). We also wanted to connect their experiences with what was observed in the self-reports. Three peer debriefing audits were arranged to validate the procedure (Lincoln \& Guba, 1986). One independent researcher was invited to analyze the process of analysis. This researcher was not involved in any part of the research but was familiar with the methodologies used in the qualitative analysis.

Although alexithymia should be viewed as a continuous variable, and some researchers refer to patients as having low and high levels of alexithymia, to differentiate qualitatively the cases, we will refer to cases as alexithymic (high levels of alexithymia) and non-alexithymic (low levels of alexithymia). All clients' names are fictional.

\section{Results}

Table 2 presents the significant changes considering the RCI and Figure 1 presents the results for each dyad regarding the therapeutic alliance.

\section{Non alexithymic cases}

\section{Case 3-Tamara a non-alexithymic good outcome case}

Tamara was a female in her early forties, married and employed. She mentioned relational problems as the main reason for initiating psychotherapy, which was reformulated in terms of lack of assertiveness. She was seeing a psychiatrist, and was prescribed with antidepressant and anxiolytic medication. She attended couples therapy 10 years ago. In the present study she had 14 sessions of CBT with a male psychotherapist. It was considered a good outcome case from both client and therapist's perspectives.

Table 2. Change considering the reliable change index (RCI) and Status of the case.

\begin{tabular}{|c|c|c|c|c|c|c|c|c|c|c|c|}
\hline \multirow{2}{*}{$\begin{array}{l}\text { Variable } \\
\text { Session }\end{array}$} & & & \multicolumn{3}{|c|}{$\begin{array}{c}\text { Alexithymia } \\
(\text { TAS-20)RCI TAS-20 }=12.70\end{array}$} & \multicolumn{3}{|c|}{$\begin{array}{l}\text { Symptoms severity } \\
\text { (BSI)RCI BSI }=0.89\end{array}$} & \multicolumn{3}{|c|}{ Status of the case } \\
\hline & & & $1^{\text {st }}$ & $8^{\text {th }}$ & $16^{\text {th }} /$ End & $1^{\text {st }}$ & $8^{\text {th }}$ & $16^{\text {th }} /$ End & & & \\
\hline \multirow[t]{2}{*}{ Good outcome } & Alexithymic & Case 4 & 76 & 67 & $58 *$ & 2.26 & 1.92 & $.92 *$ & \multicolumn{3}{|c|}{ Completed therapy(12 sessions) } \\
\hline & Non alexithymic & Case 3 & 43 & 41 & 36 & .77 & .38 & .25 & \multicolumn{3}{|c|}{ Completed therapy (14 sessions) } \\
\hline \multirow[t]{2}{*}{ Poor outcome } & Alexithymic & Case 11 & 67 & 64 & 72 & .98 & .7 & .66 & \multicolumn{3}{|c|}{ Dropout(after session 18) } \\
\hline & Non alexithymic & Case 2 & 50 & 52 & 46 & .87 & .7 & .92 & \multicolumn{3}{|c|}{ Ongoing } \\
\hline \multicolumn{3}{|l|}{ Variable } & \multicolumn{3}{|c|}{$\begin{array}{l}\text { Difficulty Identifying } \\
\text { Feelings RCI = } 7.19\end{array}$} & \multicolumn{3}{|c|}{$\begin{array}{l}\text { Difficulty Describing } \\
\text { Feelings } \mathrm{RCI}=6.92\end{array}$} & \multicolumn{3}{|c|}{$\begin{array}{l}\text { Externally Oriented } \\
\text { Thinking RCI }=7.87\end{array}$} \\
\hline Session & & & $1^{\text {st }}$ & $8^{\text {th }}$ & $16^{\text {th }} /$ End & $1^{\text {st }}$ & $8^{\text {th }}$ & $16^{\text {th }} /$ End & $1^{\text {st }}$ & $8^{\text {th }}$ & 16th/End \\
\hline \multirow[t]{2}{*}{ Good outcome } & Alexithymic & Case 4 & 31 & 25 & $23^{*}$ & 21 & 19 & $14^{*}$ & 24 & 23 & 21 \\
\hline & Non alexithymic & Case 3 & 14 & 14 & 10 & 9 & 8 & 6 & 20 & 19 & 20 \\
\hline \multirow[t]{2}{*}{ Poor outcome } & Alexithymic & Case 11 & 20 & 17 & 24 & 25 & 23 & 23 & 22 & 24 & 25 \\
\hline & Non alexithymic & Case 2 & 13 & 16 & 15 & 16 & 15 & 13 & 21 & 21 & 18 \\
\hline
\end{tabular}

*Significant change considering the RCI. 
Since she started therapy with a GSI inferior to the RCI (Table 2) her perspective on change was considered to determine outcome. In the interview, Tamara appeared as an open, empowered and pragmatic person.

Therapeutic alliance: both therapist and client reported good levels of alliance quality (Figure 1):

"I think it was always very good. I think it has always been a very good relationship. I always opened my heart, always said what I thought and always trusted him. There was always a great empathy. I think it went very well." Tamara's interview - 8'37"

"I do not think there had been a great progress in the relationship. I think it was a client relatively easy to relate. (...) I would say that there were some hints of dependence on me, but since it was not a long therapy I do not believe that this dependence has been particularly significant." Therapist's interview - 8'02"

Emotional processing and change process: Tamara used to feel overwhelmed by her emotions usually trying to accommodate the needs of others, and started being able to tolerate those emotions. She also mentioned that she felt she was still changing:

"I feel it changed some relational problems, they have not been totally solved [laughter] but I think the fact that I have changed... because I have changed, and I am still changing, (...) I feel stronger, I feel more confident, (...) I think more about myself, (...) I would always think first of others." Tamara's interview - 3'30"
"I was very sad, very, very sad, very depressed, very sad about my life not taking action... a passive life (...) Before I would feel deeply sad, now I try to think of other things, (...) I'm a little upset but it is not that deep sadness, the feeling of abandonment that I had... no!" Tamara's interview - 2'53"

The therapist also acknowledged those changes although he had the perception that her being too intuitive may had difficult the awareness of some of her internal processes:

"This part of her intuitiveness. (...) I felt compelled to a work of 'let's see what has been done, let's see what has been done, let's go review what has been done.' In order to try to structure the changes she was doing because she alone did not do it." Therapist's interview - 12'21"

Regarding her emotion difficulties, the therapist felt they were more associated with the expression of needs in the context of her relationships rather than a difficulty in understanding her internal world:

"Even those difficult issues I was talking about earlier in her experiencing those emotions, were more in a relational context rather than an internal affective." Therapist's interview - 13'50"

Considering the change process the therapist mentioned:

"This change basically happened this way, i.e., first the work done was focused on her gaining some
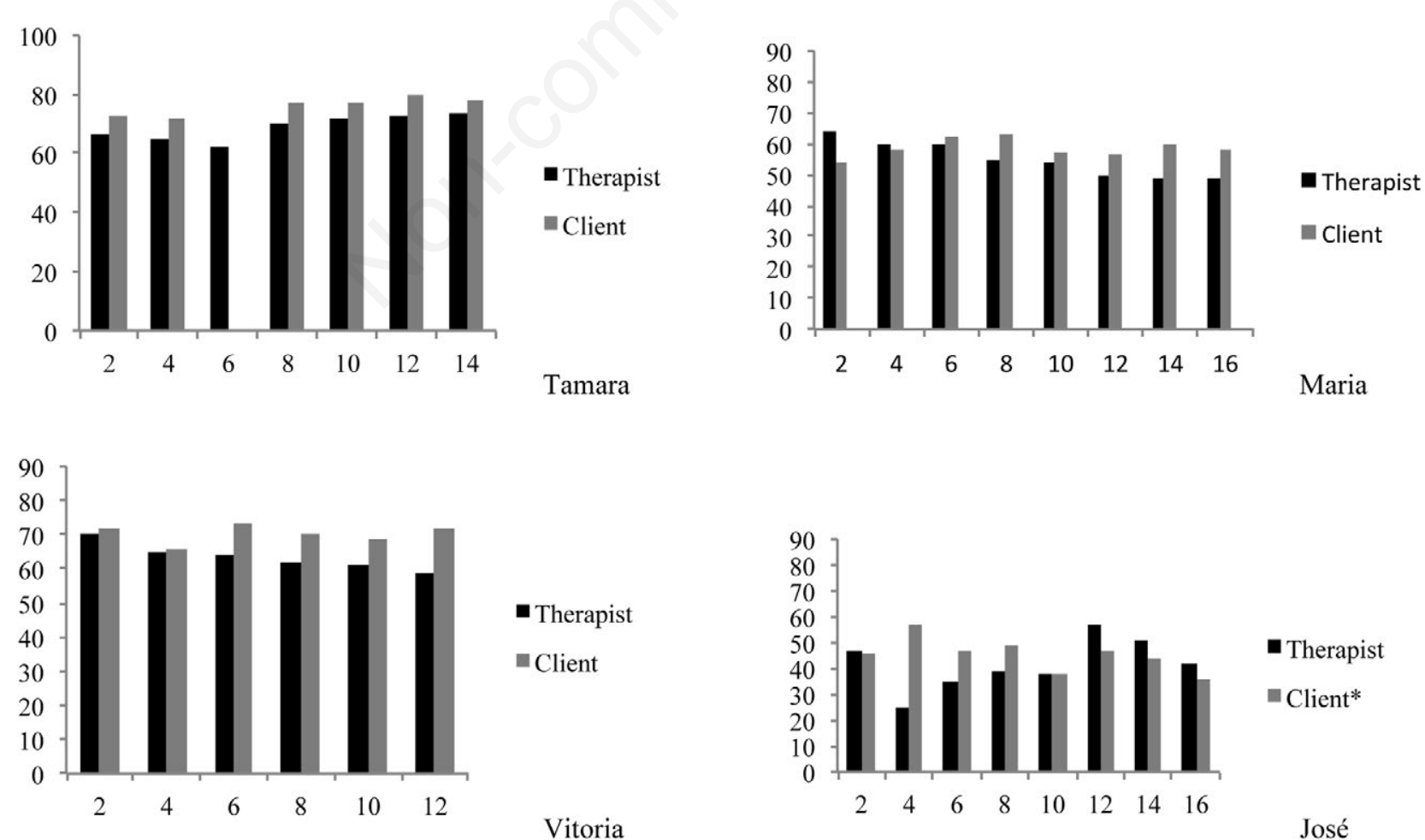

Figure 1. Therapeutic alliance through therapy. (*two missing items from client in all assessments). 
awareness of her needs and rights, then she rehearsed being assertive, and the fact that she rehearsed being assertive made her realize these things." Therapist's interview - 2'58"

This was a non-alexithymic good outcome case. Both therapist and client perceived a good relationship. The patient focus on a specific conflict allowed a short therapy. Tamara was aware of her emotions and her emotion regulation difficulties, and was aware of what caused it. Compared with the next cases, the therapeutic alliance seemed more fluid and Tamara described her problems by focusing on what she had to change. She started managing her emotions, tolerating them, acknowledging her needs and was also able to express them without feeling guilty.

\section{Case 2-Maria a non-alexithymic poor outcome case}

Maria was a female in her late sixties, married, mother of two, and grandmother of three. She was a researcher planning her retirement. Maria was concerned about memory loss, and was afraid of having Alzheimer's disease. After a psychological assessment this possibility was excluded and the results pointed to internal conflicts better explaining those memory losses. Maria was referred to psychotherapy, to focus on her relational problems, and was taking antidepressant and anxiolytic medication. She had been in psychotherapy 10 years ago, because of $a$ nervous breakdown. For this study the client completed 16 sessions of CBT with a female psychotherapist. This was considered a case in progress: therapist considered that Maria was beginning to make some changes, while the client felt that there were no changes.

Therapeutic alliance: according to the interviews, both participants perceived a developing good relationship. The client reported a higher level of quality at the end, with small fluctuations throughout the process (Figure 1).

"I believe that we feel empathy, we have maintained a good relationship. (...) is hard to start something with someone that we don't... and it is maintained, maybe growing a bit... so I trust (...) Of course I still trust that there may be some results otherwise I wouldn't come here. I don't come here to pass time." Maria interview - 21'21"

Curiously, the therapist was reporting a decrease in the quality of the alliance (Figure 1), although in the interview she mentioned an increase in its quality. The therapist felt the client was moving from a focus on external problems to a focus on herself, feeling that this was the main gain in therapy at that point:

"We are now on the necessary ground, that is the land inside Maria; a more emotional soil. (...) In the beginning we had here the blockade of rationality, and it was also hard for me to go there, to those key points and to the emotional part of Maria. (...) It was very complicated, because she didn't know how to deal with those emotions, there is still work to do regarding that." Therapist's interview $-14^{\prime} 10^{\prime \prime}$
Emotional processing and change process: during the interview Maria focused on external events/problems since she felt there hasn't been any change in those areas. It was noticeable her feeling overwhelmed, sense of lack of support and control:

“(...) Since we started [psychotherapy] I got worse. I am worse, worse and worse. (...) I believe it helps me to have someone to talk to, and also gives some additional comments. If I see any difference? I don't. The problems continue and I don't know how to deal with them." Maria's interview - 6'34"

After exploring client's and therapist's perspectives, this seems her way of functioning, avoiding her inner world. The client acknowledged it, assuming that she usually took refuge in the workplace to avoid the problems at home, which is also acknowledge by her therapist.

"I always had serious problems, very serious problems at home, but I always took refuge at my work. When I was working I forgot the problems." Maria's interview - 9'35"

"Regarding emotions, she has been experiencing some difficulties for the last years, because she is a person who lived things superficially. She never got too emotionally involved because she always protected herself like that." Therapist's interview - 1'26" Regarding emotional processing, her difficulties were mainly focused with emotion dysregulation. When specifically asked about how she managed her emotions she replied:

"I don't know, I don't do anything. Lately I live on drugs. The physician prescribed an antidepressant and a sleeping pill." Maria's interview - 23'43"

Over the years this way of functioning made it difficult for Maria to deal with her emotions. In addition, the avoidance of emotion expression made it harder to access the information associated with the emerging emotions and to develop strategies to deal with the exterior world. It seems that Maria may have been gaining something in therapy because as she mentioned: "It's better to have someone to talk to, because not having someone to talk to... because we don't talk about these issues with anyone, right? "(Client interview -14'58"). Nevertheless, she was still overwhelmed by her emotions, which appeared unproductive and devastating.

Throughout these 16 sessions, the therapist felt several difficulties in the therapeutic process:

"rationalization difficult therapy; the need she has to always bring her rational side and, at a certain point, I did not know how to deal with this rational side of Maria. At one point I also felt the need to be rational. (...) on one hand this may have been the reason for changes but on the other may not have helped in the process of exploring Maria's inner world." Therapist's interview - 24'10"

The client seems to have a lack of social support and 
described therapy as a venting process. Also, she did not seem to understand the goal of some therapeutic interventions and how they relate to her difficulties.

"I guess I feel better when I come [to therapy] than when I don't, but I think it is because I am able to unburden. "Maria's interview - 16'07"

"I don't know how to quantify... for example, some readings that she [the therapist] indicated, I believe they give... although I think that they don't apply to me. They give a perspective about life. (...) we take some learning for life and stuff... Regarding my particular problem I don't know... He [the author] also helps dealing... to accept what happens. (...). I don't know if I am able to accept that situation (...)" Maria's interview - 17'58'.

This was an ongoing non-alexithymic poor outcome case. There was an increasing quality in the therapeutic alliance, but the client reported feeling worse. Although the therapist believed they had a good relationship, she did not seem aware that it was decreasing as therapy progress. Nevertheless, the therapist was aware of the case challenges and tried to surmount them. When compared with the first case described - Tamara - Tamara's sense of being overwhelmed was different because it was focused on a specific issue, while Maria was overwhelmed with several problems. Also, the perception of Tamara's problems was different because her goals were formulated in terms of internal changes and she and her therapist seemed more attuned. Maria was aware of her emotions but tended to remain externally focused and avoidant of her internal processes. The therapist also admitted to finding this internal focus difficult, thereby both parties potentially remained avoidant of emotional processing which is likely to have contributed to ongoing difficulties in the therapeutic process. Also, there seems to be a gap between Maria's goals and her therapist interventions, represented by the fact that she was having difficulty in understanding the goal and relevance of some interventions.

\section{Alexithymic cases}

\section{Case 4 - Victoria an alexithymic good outcome case}

Victoria was a female in her early sixties. She was retired but worked with her husband in a family business. Victoria mentioned that her main problem was feeling depressed. The therapist detailed that her depression was associated with several unresolved grief processes. She was seeing a psychiatrist, and took anxiolytic and antidepressant medication mainly for sleeping, which she mentioned not needing by the end of therapy. She had no previous psychotherapy. She currently had 12 sessions of CBT with a male psychotherapist. This was considered a good outcome case from both client and therapist's perspectives. Victoria was considered alexithymic (TAS-20 $=76$ ). Table 2 shows that Victoria had a significant positive change in both alexithymia and symptoms' severity. She showed a significant decrease in difficulty identifying and describing feelings but no changes were observed in external oriented thinking. Victoria emerges as a pleasant person in the interview, talking freely about several events in her life.

Therapeutic alliance: the therapeutic alliance was perceived by the client as good. Victoria described it more focused on the bond component, comparing it to a friendship:

"There was, there was, yes [empathy], but then I believe we build up a friendship and we talked about other things (...)". Victoria's interview - 11'12"

When observing Figure 1, Victoria reported high levels of alliance quality throughout therapy. The data from the therapist also pointed to good levels, although a decrease in its quality was observed. Integrating the data from the interview it is understood that:

"...sometimes it was difficult to deal with the variables related with empathy (...) she was a person a bit dull, alexithymic. And sometimes for you to understand, that is, one has to have emotional markers to understand what's happening in therapy and that turned out hard because on this client was hard to identify emotional markers and even harder to verbalize them." Therapist's interview - 5'44"

From this excerpt it is observable that the therapist sensed the client as alexithymic and mentioned difficulties in the alliance which he associated with that. One interesting aspect was that this decrease in the alliance quality from the therapist's perspective did not seem to have affected the client's experience. Perhaps being aware of this aspect made it possible for the therapist not to act on it, as will further be illustrated.

Emotional processing and change process: when asked about emotions and emotional changes she usually responded yes/no and did not elaborate, using physical terms, for example:

"At first it was a squeeze, but I think that it is also passing. (...) to release this tension that I had, that anguish at... at... chest anguish, I think that had pass now, at least if not completely at least 95\%." Victoria's interview - 9'39"

The therapist observed that the client's changes were mainly symptomatic, which was her initial goal to relieve the depressive symptoms. This seems to be coherent with her symptomatic and alexithymia changes. Victoria made an unclear description of change, which she attributed to cognitive changes:

"not thinking of certain aspects the way I thought, I think it helped not being so depressed, right?" Victoria's interview - 16'23"

"At the beginning she was slightly dull, with a face with little expression, the speech very narrative and cut, without great elaboration and with some quite repetitive contents. (...) she became more expansive, more open. (...) with a more pleasant contact, (...) From a cognitive point of view we were able to work but then stopped." Therapist's interview - 6'40" Regarding the change process the therapist believed 
that he was more focused on cognitive work and Victoria responded well:

"I quite honestly think it was the work of cognitive reframing, to explore alternatives, because there was a very large component of guilt in grief and it was possible to work from a more cognitive standpoint. She engaged in some behavioral experiments and I think it was positive because it clearly opened the range of perspectives and I think it is a case where the cognitive work resulted in a very visible way." Therapist's interview - 2'48"

He also mentioned that he overcame the empathy difficulties:

"when we started to put together some things related to her narrative, I could see that there were things that were part of her functioning and how she related to others, that perhaps was with a lower agreeableness, with less ability to disclose because of her personal history. And maybe that helped... (...) I stopped seeing her like a distant person almost like 'because I do not want to relate to you' (...) but maybe one person that story makes sense (...) When I could conceptualize something, I think that I did well in terms of empathy towards the patient." Therapist's interview $-9^{\prime} 20^{\prime \prime}$

From the interview it is understood that Victoria perceived therapy focused on advice and was sometimes imprecise in her report of changes:

"I would talk to the THERAPIST, he would speak and I would think, and then I said 'maybe he is right', first I thought he wasn't right, but we... I believe we have a good relationship and in session I would agree with him but then I would come outside and questioned if it was like that. But things evolved and I believe he is right in is words and I have been feeling freer. "Victoria's interview - 7'10"

This was a complete good outcome alexithymic case. Victoria had an initial high level of alexithymia that significantly decreased. This is an interesting result since there were a small number of sessions for alexithymia to decrease. The therapist identified in the client aspects that he considered alexithymic characteristics and although the quality of the therapeutic alliance decreased over time, he was aware of it - specifically regarding empathy. This awareness and integration of information in the case conceptualization made it possible to overcome those difficulties.

Considering the data from the interview we could hypothesize that Victoria still presents some alexithymic characteristics such as not elaborating regarding emotional processing, or talking about emotions associated with physical terms. This is actually interesting considering her results on the alexithymia subscales: she significantly reduced her difficulties in identifying and communicating feelings, but not the external oriented thinking. Taylor et al. (2016) argue that is possible that patients with secondary alexithymia to show changes in their level of emotional awareness as they shift back and forth on the continuum between affective agnosia and anomia.

Previous studies in grief therapy (Ogrodniczuk et al., 2005) showed that difficulty in communicating feelings and a tendency to engage in externally oriented thinking were associated with less favorable outcome and that this relationship was mediated by therapist reactions to the patient. In our study even though the therapist experience was affected by the client alexithymia, the client experienced a good outcome.

Compared with the previous cases, Victoria seemed less articulate regarding the change process. Comparing Victoria to Maria, a major difference seems to be on how she perceived the process, and although less articulate, Victoria was more focused on what she could change rather than an external change. The therapist also mentioned the need to do cognitive work, because of the client's functioning, but they seemed more attuned than Maria and her therapist. Although Maria was also more rational, it was felt by the therapist as a major blockage. Victoria's therapist was able to integrate her difficulties in case conceptualization and saw the usefulness of going with her rational part, making use of it to achieve their therapeutic goals.

\section{Case 11 - José an Alexithymic poor outcome}

José was a male in his early twenties, college student and single. His chief concern was feeling depressed. He had one previous inpatient treatment after which he was advised to do psychotherapeutic outpatient treatment. He was seeing a psychiatrist and took antidepressant and mood-stabilizing medication. He completed 16 sessions of CBT with a male psychotherapist. It was considered a poor outcome case from both client and therapist's perspectives. In the last assessment, the client was considering ending therapy, which happened two sessions latter. The client was considered alexithymic (TAS-20 $=67)$ and presented no significant decrease in the outcome measures. When considering the different alexithymia components, it's observed that, although not significantly, he scored a bit higher at the last assessment in difficulty identifying feelings and external oriented thinking. The therapist considered that José was alexithymic and considered the possibility of a schizoid personality disorder. José presented himself as a very private person and seemed uncomfortable during the interview. José appeared older than is actual age, and talked in a very low tone of voice, responding frequently by nodding or with yes, no or exactly/right answers. It appears from the therapist's interview that he felt that most of the time he would have to guess how José was feeling depending on the context. José mentioned feeling frustrated about therapy because he felt no changes and he even referred leaving the sessions more depressed.

Therapeutic alliance: during the interviews, both client and therapist referred to difficulties in the alliance. The 
quantitative data from the client (Figure 1) should be interpreted considering that he systematically did not respond to two items: I believe that my therapist likes me and I feel that my therapist appreciates me. These items correspond to the bond aspect of the alliance.

"A very professional thing [therapeutic relation], he [therapist] makes questions, I answer. Essentially is this. I have nothing to hide. I say it all, but I am not...(...) How am I supposed to explain... there is no, I am not much at ease, no...

Interviewer - You do not feel very at ease?

Patient - I do not hide anything but at the same time I do not feel at ease to talk that much. "José's interview - 7'38"

"Our relationship is obviously affected by it, i.e., although I have the feeling that I'm the person with whom he shares most of his life, I still do not exactly feel that this translates into a good relationship. I think he sees me as a Dr and even feels a bit frustrated by the therapy is not working. While again not being able to realize why it is not working, because there is no psychological explanation. (...)" Therapist's interview -9'39"

Emotional processing and change process: regarding emotional processing, there was a persistent difficulty in regulating emotions which was consistent with the results on alexithymia. José said that before the inpatient treatment he would drink heavily to regulate emotions and now he did not know how to regulate emotions.

Patient - Before the inpatient treatment I would drink. Essentially that's what I used to do. Now I try to ignore. (...)

Interviewer - And what do you feel is different now? So by then you had that escape, so to speak, but that also had setbacks... this time there is no alcohol and you have no way to cope...

Patient - No.

José's interview - 4'42"

The client mentioned many difficulties regarding emotions during the interview, and seemed ambivalent about being more expressive with other people:

Interviewer-Do you feel like a person who easily expresses emotions?

Patient - No. (...)

Interviewer - And how is it... is something that José would liked to be different? Was it always like this?

Patient - It was always like this, I'm not seeing myself changing in anyway, so...

Interviewer - Do you feel this reflects on the way people relate to you, not expressing emotions? On how you relate to yourself? If you could choose, would you like to be more expressive?

Patient -If I could choose, I do not think so. I would rather be as I am. But from what I've learned I think it would be good to change but... I do not see how.

Interviewer - So when you say that you would rather be... what make you say that? Because a part of you says "maybe for what they have told me, maybe I should do it" ...

Patient - I learned to live with it, never felt other way, I do not know how to do it differently and if I try I do not feel good with myself, I do not feel good about myself trying to do that.

José's interview $-5^{\prime} 18^{\prime \prime}$

When the interviewer tried to explore what he needed from therapy he seemed confused and did not know how to respond:

Interviewer - If you could say "what I wanted from therapy was"... The psychiatrist recommended therapy and when you came, what did you wanted to change, what would you like to happen that has not happened yet?

Patient - To be honest, I don't know [deep breath]... I do not know.

José's interview - 2'30"

The therapist noted several difficulties with this patient regarding emotional processing: the client did not have access to emotions, and could not differentiate, usually saying I feel bad; I feel good, a characteristic associated with alexithymia. The therapist saw no changes regarding emotional processing and even said at some point that the intervention was very didactic:

"this is a client who I consider a difficult client.

Why? Because he is a client who has some difficulty...

For example, if I ask him how he is, he cannot make differentiations, for example. Varies between feeling good or feeling bad, basically. Being that feeling good does not exactly mean feeling good neither feeling bad means... Then when I try to explore the emotional significance of specific things, for example, he goes play cards with some friends, than those friends have a party afterwards and he prefers not to stay. And when I try to explore the emotional experience it is extremely difficult. It is as if he had not exactly access to it. And then it is very difficult to explore things in therapeutic terms. Almost... what I've been doing with him is using a didactic logic, in the sense that I pull him to look inside and try to find a language... but often-just for you to get an idea-often it's like I am guessing the type of emotional reactions people may have in these situations, I try to explore with him the various possibilities of emotions, try to help him identify the one that has more to do with him and then try to elaborate deeper, etc... Almost in a very didactic and very constructive logic, brick by brick. Obviously this takes time."

Therapist's interview - 2'50"

The therapist said that he felt as a major difficulty the way the client conceived his problems. José was able to bring factual descriptions of situations but did not have an internal theory about it:

"An example of difficulties: in integrating, for example. He can see that he does not have many friends, 
right? When exploring, we can realize that what makes it difficult is the initial contact and then we try to understand the contexts that hinder these difficulties in emotional contact. Then what is his emotional reaction? That is, how would he feel if he made that contact, or how does he feel for not making that contact? And then to think in terms of expectations: what does he imagine would happen in terms of contact? But often this is done in such a way that it is almost as if he had to discover these things for the first time.(...) It's almost as if we were still translating external problems in inner things."

Therapist's interview $-5^{\prime} 20^{\prime \prime}$

The therapist perceived the client as alexithymic and named the reasons:

"I think this is an alexithymic patient. This client has alexithymic traits. (...) I identify them in the way he lives emotions, he describes emotions and how he describes living emotions. (...) This client has difficulty talking about his emotional experience. And I do not think it's just a matter of expression, it is really a matter of experience. (...), it's like if you ask me questions of integral calculus, I cannot grasp the concepts you're talking about. And it's almost as if he's describing emotional situations, and when I talk to him or when we dialogued is almost as if we were speaking a different language.

Therapist's interview - 13'12"

This seems in line with Ogrodniczuk et al. (2005) study, where patients with alexithymia may have poorer outcomes in part because their therapists perceive them less compatible with them. The therapist reveals that the most relevant aspects of therapy were helping the patient identify emotions and translate events into psychological experiences:

"Roughly the joint objectives are at an interpersonal level, i.e., to facilitate the connection between him and others. (...) The goals of therapy are to do emotional exploration in order to identify a joint narrative that fits the problem. (...) In this case...at this point I realize it is very indifferent or not...to have a theory of his problem or a conceptualization of his problem. It is very, very important to identify the little things, to help him identify and process...Almost like a skills training more than exactly a...one...therapy...it is therapy but it is not exactly an exploration of a central question to him."

Therapist's interview - 7'13"

This was a poor outcome case with the client dropping out. The therapist perceived the client as alexithymic and attributed some of the difficulties with the therapy to that impairment. They both felt that the relationship was affected - the therapist by this emotional experiencing difficulty; while the client named the relationship as professional, like it was not emotionally involved. The therapist suggested that the client had a schizoid personality disorder. Compared with Victoria, one of the main differences was associated with the relationship: although in both cases the relationship was affected by alexithymia, Victoria perceived the relationship as good and emotionally involved; José showed a deeper difficulty in connecting with other people that, as previous illustrated, seemed ego syntonic. Also the tasks/techniques to achieve the therapeutic goals seemed in the range of Victoria's abilities, unlike José, that showed a higher difficulty in engaging in tasks promoted by his therapist. Although both poor outcome cases, Maria and José, had emotional difficulties and their problems were not translated into an internal change language, as Victoria, Maria was able to emotionally connect with the therapist, even if she had difficulty identifying how and what she could change. José was referred to psychotherapy, and he even mentioned he was hopeful at the beginning, but when specifically asked, he was not able to name what he wanted from therapy. Emotional expression facilitates reflection, narrative building and meaning making, and José felt difficult to express emotions. This had an impact on the therapeutic alliance and made it difficult for other therapeutic interventions to unfold as the therapist expected. We could also hypothesize some interpersonal dysfunction, which could also be seen at the interview with the interviewer tending to do some closed questions. Not only the client tended to respond with yes and no to questions, but also the interviewer (such as the therapist?) started promoting that kind of interaction.

\section{Discussion}

\section{Alexithymia construct}

Alexithymia seems a useful construct, and may be constructive to integrate it in case conceptualization. Nevertheless, it should be noted that its impact may depend upon other characteristics, and other variables should be taken into account, including personality, severity of the diagnosis and emotional difficulties. These aspects are well illustrated from the cases of Victoria and José, and even though Victoria started with a higher score at the TAS-20, showed a better therapeutic outcome. José's difficulties, even though associated with alexithymia, seemed more severe has he may have a personality disorder.

Individuals with high levels of alexithymia pose an additional challenge in psychotherapy since they are impaired in their ability to experience and express distress and other subjective feelings - not only they are in distress, they have a difficulty in communicating that distress to the therapist (as illustrated in Jose's case). Although alexithymia has been predominantly seen as a personality construct we reiterate that alexithymia should not be thought of as a disorder, but as a psychological characteristic of thought, feelings and underlying processing. So it should not be though regardless of other characteristics of the client at that moment in his/her life and should be 
considered both as a trait and a state phenomenon. Also, we believe the different features of the construct play an important role in psychotherapy and have an influence on the therapeutic alliance since it influence the perspective the therapist have on the client, so how each specific influence the process should be considered.

\section{How do client and therapist experience the relationship? Do they perceive the difficulties in the relationship due to alexithymia?}

Both therapists of clients who scored high in the TAS20 in this study perceived the client as alexithymic. The therapists related their difficulties in being empathic and in conducting the treatment to the client's alexithymic characteristics - difficulty expressing feelings, difficulties in emotional experiencing, not having emotional markers which led to the need of focusing on cognitive tasks. Though we can partially attribute the difficulties to this aspect, as can be observed by the therapists' descriptions, there are other information that can be related with these difficulties as discussed in Jose and Vitoria's cases. Jose's case was more complex and he showed a deeper difficulty in connecting with people in general - a difficulty that appears in the core of his problems. Curiously, at the interview it's observed that the interaction is sometimes based in closed questions. Since the relationship is not only dependent on one intervenient, it could be hypothesize that the posture of Jose interfered with the interviewer posture (or was it the other way around?). How could this cycle be overcome?

Also, the tasks/techniques to achieve the therapeutic goals were in the range of Victoria's abilities, unlike José, who showed greater difficulty in engaging in some tasks and seemed ambivalent regarding change. Although in both alexithymic cases the relationship was affected, Victoria perceived it as a good relationship, emotionally involved and had some theory regarding her problem.

\section{How is that different from the difficulties felt in the therapeutic alliance with other patients?}

It is not new that the alliance poses a great impact in the therapeutic process and consequently in the therapeutic outcome. Maria's therapist - a poor outcome case nonalexithymic - also reported a decrease in the alliance, which seemed associated with a more rational and less emotional way of processing events. From the therapist perspective, these difficulties were associated with the patient's lack of emotional processing competencies and her focus on external events. Although associated with emotional processing, these difficulties do not seem associated with an alexithymic functioning. It's hypothesized that there was a difficulty related with the tasks in therapy, since the client didn't understand the goals of some interventions. Maria was aware of her functioning and although presenting somatic symptoms did not verbalize emotions in a somatic way, as Victoria did. Tamara, a good outcome non-alexithymic case, although presenting some difficulty regulating emotions and dealing with other significant emotions, was aware of them. Comparing her to Maria, her sense of being overwhelmed was different because it was more focused on a specific issue, while Maria was overwhelmed with several problems. The perception of Tamara's problems was also different because the issues were formulated in terms of internal changes and not other's changes.

\section{What special care should be taken with alexithymic patients in psychotherapy?}

In clinical work, it is widely recognized that dealing with different types of difficulties related to the therapeutic alliance is essential to the course of therapy (for a review see Doran, 2016). Decades of research on the relationship between psychotherapists and patients show that the quality of alliance, especially as perceived by the client, correlates positively with the outcome. The working alliance has also been touted as the essential ingredient in promoting therapeutic change (Lambert \& Simon, 2008). Nevertheless, it has also been commonly experienced among clinicians that with some patients, particularly patients with severe psychological conditions, an initially poor alliance which had endured for many sessions may eventually be repaired and turn into a good one. That is, a strong alliance isn't on its own enough to make therapy effective, instead a strong alliance can be the result of effective interventions: working hard in therapy together eventually brings about a good alliance; both parties have to work on rupture and repair (Rabu, Halvorsen, \& Haavind, 2011; Safran, Muran, \& Eubanks-Carter, 2011). In the presented cases, perhaps Maria and Jose could make this path. This development was partially observed in Victoria's therapy. One question remains: is the ability to build a relationship one of the core aspects of therapy with patients with alexithymia? How does it correlate with other types of changes (emotional, cognitive)?

Also, patients who improve in psychotherapy evolve in the expression of external events in a disconnected way to a focus on internal feelings described in detail and form associated with each other, thus accessing the emotions necessary to promote action trends prone to solving problems (Greenberg, 2002; Rogers, 1959). These difficulties are present in alexithymic patients, but they do not seem specific to them as illustrated by Maria, a non-alexithymic poor outcome case. Cases with emotional impairments - being overwhelmed, more focused on the exterior, and more rational, even if not alexithymic - may bring additional difficulties to the relationship. Considering our results, we hypothesize that to develop empathy towards a patient with alexithymia it's necessary to make sense of his/her emotional difficulties, to overcome some frustration towards some lack of emotional markers to minimize ruptures.

What seems comprehensible from our research is that it is important that the therapist can adapt and recognize his/her own emotional reactions as tools to create better in- 
terventions. Avoiding ruptures may not be possible - in fact trying to avoid ruptures may make the alliance dysfunctional, but it is important to minimize them and make sense of them in light of case conceptualization. A RCT or effectiveness study addressing the differential impact alexithymia have in the outcome considering interventions promoting emotional processing skills, cognitively and emotionally, and how the therapist feelings/resistance poses limitations to those interventions, could bring new developments in alexithymia psychotherapeutic intervention.

\section{Conclusions}

It is recognized that no single case study can do more than slightly increase the accuracy and credibility of a theory (Stiles, 2005). Likewise, insofar as the authors are fallible and come with preconceptions, it is likely that at least some aspects of the cases would be interpreted differently by different observers. We have tried to address this by presenting enough verbatim material to allow readers to form some impressions of their own. A major limitation is that not all cases were complete psychotherapies - even being focused on the processes and the differential impact alexithymia has on therapy, it is understood that some cases are more complex and may need more time to accomplish change. A research wishing to study the alexithymia construct would become richer if included several measures of the construct, such as an alexithymia interview. Even though the TAS-20 version for the Portuguese population presented good psychometric properties, considering that the TAS-20 asks to use introspection to subjects who are supposed to have deficits in affective (self)awareness it would have enriched the discussion and the comprehension of cases. All our conclusions cannot stand firm without further replication with sounder multi method assessment. Also, case studies wishing to study processes in psychotherapy become richer when it is possible to cross quantitative data with observations of sessions, or excerpts of sessions, which allows access to what is done and not only the participant's report of the process. Moreover, follow ups would have permitted access to further development of the clients which would be helpful to additional understand alexithymic functioning. in addition, longer therapies should be included and with different therapeutic orientations. We believe that more research is needed on this matter and we hope this study stimulates further investigation on case study on alexithymia.

\section{References}

Bagby, R.M., Parker, J.D., \& Taylor, G.J. (1994a). The TwentyItem Toronto Alexithymia Scale -I. Item selection and crossvalidation of the factor structure. Journal of Psychosomatic Research, 38(1), 23-32. doi: 10.1016/0022-3999(94)90005-1

Bagby, R. M., Parker, J. D. A., \& Taylor, G. J. (1994b). The
Twenty-Item Toronto Alexithymia Scale-II. Convergent, discriminant, and concurrent validity. Journal of Psychosomatic Research, 38 (1), 33-40. doi: 10.1016/0022-3999 (94)90006-X

Barkham, M., Connell, J., Stiles, W. B., Miles, J. N. V., Margison, F., Evans, C., \& Mellor-Clark, J. (2006). Dose-effect relations and responsive regulation of treatment duration: The good enough level. Journal of Consulting and Clinical Psychology, 74(1), 160-167. doi: 10.1037/0022-006X.74.1.160

Bordin, E. (1979). The generalizability of the psychoanalytic concept of the working alliance. Psychotherapy: Theory, Research and Practice, 16, 252-260. doi: 10.1037/h0085885

Brady, R. E., Bujarski, S. J., Feldner, M. T., \& Pyne, J. M. (2017). Examining the effects of alexithymia on the relation between posttraumatic stress disorder and over-reporting. Psychological Trauma: Theory, Research, Practice, and Policy, 9(1), 80-87. doi: 10.1037/tra0000155

Braun, V., \& Clarke, V. (2006) Using thematic analysis in psychology. Qualitative Research in Psychology, 3(2), 77-101.

Canavarro, M.C. (1999). Inventário de sintomas psicopatológi$\cos$ (BSI) [Brief Symptoms Inventory (BSI)]. In M.R. Simões, M.M. Gonçalves, \& L.S. Almeida (Eds.). Testes e provas psicológicas em Portugal (vol. 2, pp 87-94). Braga, Portugal: APPORT/SHO.

Cameron, K., Ogrodniczuk, J., \& Hadjipavlou, G. (2014). Changes in alexithymia following psychological intervention: A review. Harvard Review of Psychiatry, 22(3), 162-178.

Caslini, M., Rivolta, L., Zappa, L.E., Carrà, G., \& Clerici, M. (2015). Psychotherapeutic treatment of eating disorders improve dissociative experiences and impulse regulation but not alexithymia. A case series report. Rivista di Psichiatria, 50(3), 143-147.

Christensen, L., \& Mendoza, J.L. (1986). A method of assessing change in a single subject: An alteration of the RC index. Behavior Therapy, 17(3), 305-308. doi: 10.1016/S00057894(86)80060-0

de Haan, H.A., Schellekens, A.F.A., van der Palen, J., Verkes Buitelaar, J.K., \& De Jong, C.J. (2012). The level of alexithymia in alcohol-dependent patients does not influence outcomes after inpatient treatment. The American Journal of Drug and Alcohol Abuse, 38(4), 299-304. doi: 10.3109/00952990.2012.668597

De Panfilis, C. Ossola, P. Tonna, M., Catania, L. Marchesi, C. (2015). Finding words for feelings: The relationship between personality disorders and alexithymia. Personality and Individual Differences, 74, 285-291.

Derogatis, L.R. (1975). Symptom Checklist-90-Revised (SCL90-R). Minneapolis, MN: NCS Assessments.

Dong, S., Ju, Q., Qiu, T., \& Feng, S. (2017). Intervention effect of group treatment on different types of alexithymia Chinese Journal of Clinical Psychology, 25(2), 304-309.

Doran, J.M. (2016). The working alliance: Where have we been, where are we going? Psychotherapy Research, 26(2), 14663. doi: 10.1080/10503307.2014.954153

Elliot, R., \& Shapiro, D.A. (1992). Client and therapist as analyst of significant events. In S.G. Toukmanian, \& D.L. Rennie (Eds.). Psychotherapy process research. Pragmatic and narrative approaches (pp. 163-186). Newbury Park, CA: Sage.

Evans, C., Margison, F., \& Barkham, M. (1998). The contribution of reliable and clinically significant change methods to evidence-based mental health. Evidence Based Mental Health, 1(3), 70-72. doi: 10.1136/ebmh.1.3.70

Gay, M., Hanin, D. \& Luminet, O. (2008). Effectiveness of an 
hypnotic imagery intervention on reducing alexithymia. Contemporary Hypnosis 25(1), 1-13. doi: 10.1002/ch.344

Grabe, H.J., Frommer, J., Ankerhold, A., Ulrich, C., Gröger, R., Franke,...Spitzer C. (2008). Alexithymia and Outcome in Psychotherapy. Psychotherapy \& Psychosomatics, 77 (3), 189-194. doi: 10.1159/000119739

Greenberg, L. (2002). Emotion-Focused Therapy. Coaching clients to work through their feelings. Washington DC: APA. doi: 10.1037/10447-000

Hill, E., Berthoz, S., \& Frith, U. (2004). Brief report: Cognitive processing of own emotions in individuals with autistic spectrum disorder and in their relatives. Journal of Autism and Developmental Disorders, 34, 229-235.

Horvath, A. O., \& Greenberg, L. S. (1989). The development and validation of the working alliance inventory. Journal of Counseling Psychology, 36, 223-233 doi: 10.1037//00220167.36.2.223

Iwakabe, S. (2011). Extending systematic case study method: generating and testing hypotheses about therapeutic factors through comparisons of successful and unsuccessful cases. Pragmatic Case studies in Psychotherapy, 7(2), 339-350. doi: $10.14713 /$ pcsp.v7i2.1094

Jacobson, N. S., \& Truax, P. (1991). Clinical significance: A statistical approach to defining meaningful change in psychotherapy research. Journal of Consulting and Clinical Psychology, 59(1), 12-19. doi: 10.1037//0022-006X.59.1.12 245

Lambert, M. J., \& Simon, W. (2008). The therapeutic relationship: Central and essential in psychotherapy outcome. In S.F. Hick \& T. Bien (Eds.), Mindfulness and the therapeutic relationship (pp. 19-33). New York: The Guilford Press.

Levant, R.F., Halter, M.J., Hayden, E. \& Williams, C. (2009). The efficacy of Alexithymia Reduction Treatment: A pilot study. Journal of Men's Studies, 17, 75-84. doi: 10.3149/jms. 1701.75

Levant, R., Williams, C. \& Hayden, E. (2008). Alexithymia Reduction Treatment (ART): A manual for a brief psycho-educational intervention for treating normative male alexithymia, group therapy format. Unpublished Manual: University of Akron.

Leweke, F. Bausch, S. Leichsenring, F. Walter, B. \& Stingl, M, (2009). Alexithymia as a predictor of outcome of psychodynamically oriented inpatient treatment. Psychotherapy Research, 19(3), 323-31. doi: 10.1080/10503300902870554

Lincoln, Y. S., \& Guba, E. G. (1986). But is it rigorous? Trustworthiness and authenticity in naturalistic evaluation. New Directions for Evaluation, 1986(30), 73-84. doi: 10.1002/ev. 1427

Machado, P. P., \& Horvath, A. (1999). Inventário da aliança terapêutica: versão portuguesa do working alliance inventory. [Portuguese version of the working aliance inventory] In M. R. Simões, L. S. Almeida, \& M. Gonçalves (Eds.). Testes e Provas Psicológicas em Portugal (vol. 2) (pp.87-94). Braga: SHO.

McCallum, M., Piper, W. E., Ogrodniczuk, J. S., \& Joyce, A. S. (2003). Relationships among psychological mindedness, alexithymia, and outcome in four forms of short-term psychotherapy. Psychology and Psychotherapy: Theory, Research and Practice, 76(2), 133-144. doi: 10.1348/147608303765951177

McGillivray, L., Becerra, R., \& Harms, C. (2018). Alexithymia stability and therapeutic outcome in an Australian psychiatric outpatient sample. Clinical Psychologist. doi: 10.1111/cp. 12148
Ogrodniczuk, J.S. (2007). Alexithymia: Considerations for the psychotherapist. Psychotherapy Bulletin, 42 (1), 4-7.

Ogrodniczuk, J.S., Piper, W.E., \& Joyce, A.S. (2005). The negative effect of alexithymia on the outcome of group therapy for complicated grief: What role might the therapist play? Comprehensive Psychiatry, 46, 206-213. doi: 10.1016/j.comppsych.2004.08.005

Parker, J.D.A., Taylor, G.J., and Bagby, R.M. (2003a). The Twenty-Item Toronto Alexithymia Scale-III: Reliability and factorial validity in a community population. Journal of Psychosomatic Research, 55, 269-275. doi: 10.1016/S00223999(02)00578-0

Petterson, R. (2004). Nameless desire: Alexithymia and the Anoretic Patient. The American Journal of Psychoanalysis, 64 (1), 77-90.

Prazeres, N., Parker, J.D., \& Taylor, G.J. (2000). Adaptação Portuguesa da Escala de Alexitimia de Toronto de 20 Itens (TAS-20) [Portuguese version of the 20- item Toronto Alexithymia Scale (TAS-20).] Revista Iberoamericana de Diagnóstico e Avaliação Psicológica, 9(1), 9-21.

$\mathrm{RaBu}, \mathrm{M}$., Halvorsen, M. S. \& Haavind, H. (2011). Early relationship struggles: A case study of alliance formation and Reparation. Counselling and Psychotherapy Research, 11(1): 23-33. doi: 10.1080/14733145.2011.546073

Rogers, C. (1959). A theory of therapy, personality and interpersonal relationships as developed in the client centered framework. In S. Koch (Ed.), Psychology: A study of a science. Vol. 3: Formulations of the person and the social context. New York: McGraw Hill.

Safran, J.D., Muran, J.C., \& Eubanks-Carter, C. (2011). Repairing alliance ruptures. Psychotherapy, 48, 80-87. doi: $10.1037 / \mathrm{a} 0022140$

Sifneos, P.E. (1973). The prevalence of 'alexithymic' characteristics in psychosomatic patients. Psychotherapy and Psychosomatics, 22, 255-262.

Silva, A.N., Vasco. A. B. \& Watson, J.C. (2013). Alexithymia and Emotional Processing as Phenomena Pertinent to all Theoretical Orientations. International Journal of Psychotherapy, 17(3), 5-19.

Silva, A.N. Vasco. A. B. \& Watson, J.C. (2018). Alexithymia and Emotional Processing: a longitudinal mixed methods research. Research in Psychotherapy: Psychopathology, Process and Outcome, 21(1), 40-54. doi: 10.4081/ripppo. 2018.292

Stiles, W.B. (2005). Case studies. In J.C. Norcross, L.E. Beutler \& R.F. Levant (Eds), Evidence-based practices in mental health: Debate and dialogue on the fundamental questions (pp. 57-64). Washington, DC: American Psychological Association.

Taylor, G.J. (1984). Alexithymia: Concept, Measurement, and Implications for treatment. The American Journal of Psychiatry, 141 (6), 725-732.

Taylor, G.J. (2000). Recent developments in alexithymia theory and research. Canadian Journal of Psychiatry, 45(2), 1-15.

Taylor, G.J., Bagby, R.M., \& Parker, J.D.A. (2016). What's in the name 'alexithymia'? A commentary on "Affective agnosia: Expansion of the alexithymia construct and a new opportunity to integrate and extend Freud's legacy." Neuroscience \& Biobehavioral Reviews. doi: 10.1016/j.neubiorev.2016.05.025

Taylor, G.J., Bagby, R.M., \& Parker, J.D.A. (2003b). The Twenty-Item Toronto Alexithymia Scale-IV: Reliability and factorial validity in different languages and cultures. Journal 
of Psychosomatic Research 55, 277-283. doi: 10.1016/ S0022-3999(02)00601-3

Taylor, G.J., Bagby, R.M., \& Parker, J.D. A (1997). Disorders of affect regulation: Alexithymia in medical and psychiatric illness. Cambridge: Cambridge University Press. doi: 10.1017/CBO9780511526831

Tracey, T.J., \& Kokotovic, A.M. (1989). Factor structure of the Working Alliance inventory. Psychological Assessment: A Journal of Consulting and Clinical Psychology, 3, 207-210. doi:10.1037//1040-3590.1.3.207

Uzun, Ö. (2003). Alexithymia in male alcoholics: study in a Turkish sample. Comprehensive Psychiatry, 44(5), 435-446.

Yin, R. K (2003). Case study research: Design and methods (3rd ed.). Thousand Oaks, CA: Sage Publications.

Zeitlan, S.B., \& Mcnally, R.J. (1993). Alexithymia and anxiety sensitivity in panic disorder and obsessive-compulsive disorder. American Journal of Psychiatry, 150, 658-660. 